\title{
First observation of the nudibranch Tenellia feeding on the scleractinian coral Pavona decussata
}

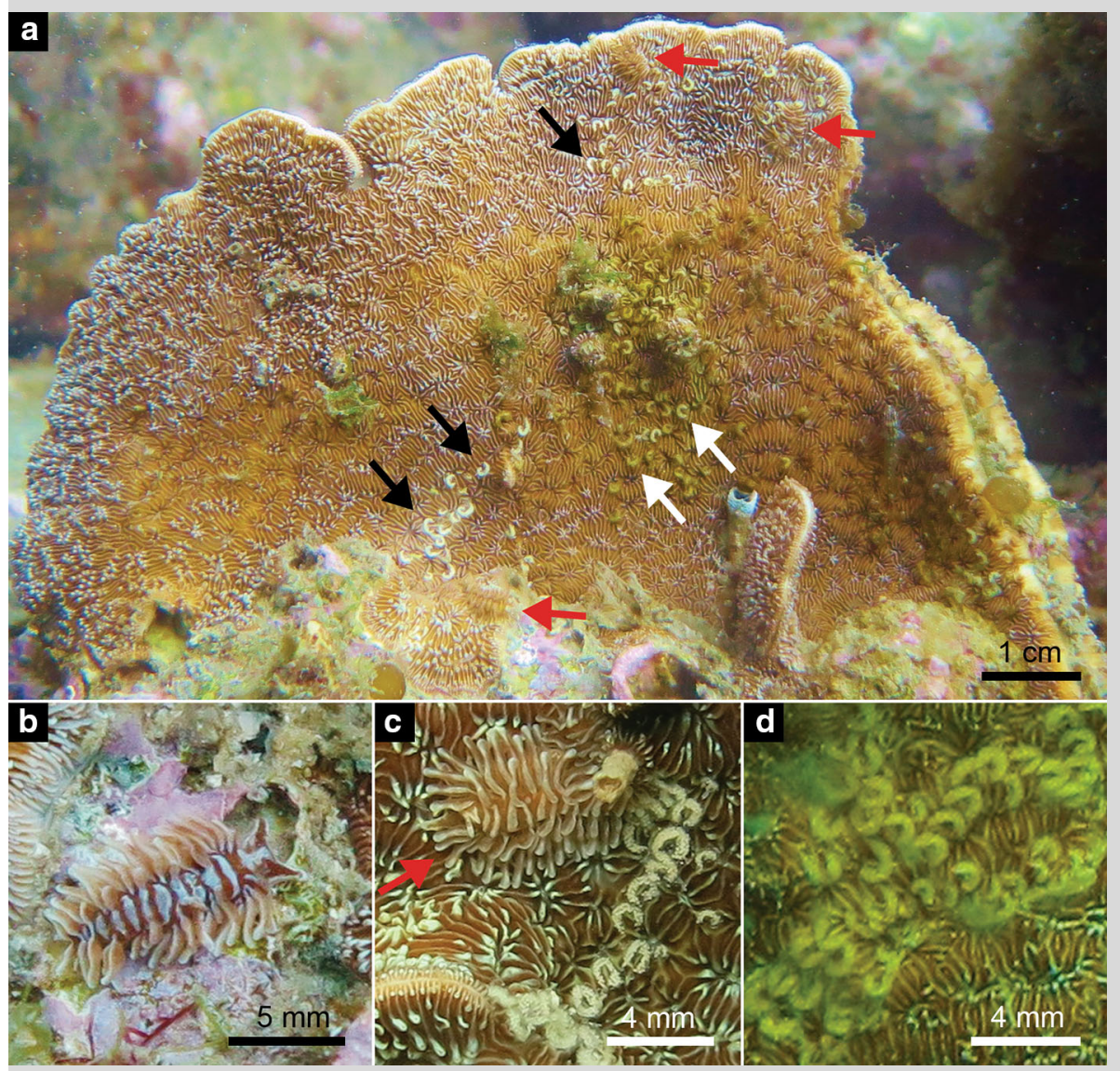

Fig. 1 a Tenellia nudibranchs (red arrows), egg masses (black arrows) and egg masses with algal overgrowth (white arrows) on a transplanted coral fragment of $P$. decussata; b close-up of a nudibranch removed carefully from $P$. decussata; $\mathbf{c}$ a nudibranch (arrow) with excellent camouflage and some egg masses; and $\mathbf{d}$ egg masses covered with algal overgrowth
Some Tenellia nudibranchs are known to be corallivores (Cella et al. 2016) that prey on poritid and dendrophylliid corals (Ritson-Williams et al. 2003). We report here the first record of a Tenellia nudibranch feeding on an agariciid coral, $\mathrm{Pa}$ vona decussata. These nudibranchs (max. length observed $\sim 10 \mathrm{~mm}$ ) were first found during detailed examination of transplanted coral fragments of $P$. decussata in Chek Chau, Hong Kong, southern China. They were subsequently also found on natural coral colonies, inflicting feeding scars along the path of their movement. These nudibranchs display excellent mimicry (Fig. 1). Their body pattern of alternating brown and white stripes closely resembles the septa of $P$. decussata (Fig. 1b, c). Their cerata are also very similar to the tentacles of $P$. decussata, which are usually extended, even in daytime. Clumps of white egg capsules (each $\sim 2 \mathrm{~mm}$ in length) (Fig. 1c) were also observed on the surface of coral colonies all year round.

High densities ( $>1$ individual $\mathrm{cm}^{-2}$ ) of Tenellia caused rapid and heavy mortality of $P$. decussata colonies grown in our laboratory aquaria. However, very low densities $\left(<1\right.$ individual $\left.\mathrm{m}^{-2}\right)$ of nudibranchs were found on natural colonies of $P$. decussata encountered in our field surveys. Coral tissue damage caused by the nudibranchs in nature was therefore limited. Predation by fishes and crus-

taceans could have limited the abundance of nudibranchs on natural coral surfaces (Gochfeld and Aeby 1997). Algae were observed rapidly growing over Tenellia egg masses (Fig. 1d), potentially affecting their hatching success. The prevalence of Tenellia corallivory on $P$. decussata in other tropical and subtropical coral communities remains to be verified.

\section{References}

Cella K, Carmona L, Ekimova I, Chichvarkhin A, Schepetov D, Gosliner TM (2016) A radical solution: the phylogeny of the nudibranch family Fionidae. PLoS One 11:e0167800

Gochfeld DJ, Aeby GS (1997) Control of populations of the coral-feeding nudibranch Phestilla sibogae by fish and crustacean predators. Mar Biol 130:63-69

Ritson-Williams R, Shjegstad S, Paul V (2003) Host specificity of four corallivorous Phestilla nudibranchs (Gastropoda: Opisthobranchia). Mar Ecol Prog Ser 255:207-218

K. T. Wong · T. Y. Ng · R. H. L. Tsang · P. Ang Jr $(\bowtie)$

Marine Science Laboratory, The Chinese University of Hong Kong, Shatin, NT, Hong Kong SAR, China

e-mail: put-ang@cuhk.edu.hk

Received: 17 May 2017/ Accepted: 17 June 2017/Published online: 24 June 2017

Coral Reefs (2017) $36: 1121$

(C) Springer-Verlag GmbH Germany 2017

DOI $10.1007 / \mathrm{s} 00338-017-1603-8$ 